\title{
Communication and Collaboration between School and Family for Addressing Bullying
}

\author{
Panagiotis J. Stamatis* and Eleni N. Nikolaou*
}

\begin{abstract}
Dept. of Sciences of Preschool Education and Educational Design, University of the Aegean, Rhodes, Greece
\end{abstract}

\begin{abstract}
School and family are the main socializing agents for children. Therefore, effective communication and collaboration between these contexts is essential, although sometimes there are barriers to school-family partnership, particularly when they try to play a more active role in the educational process. It is widely recognized that parent involvement in school has successful contributions to student school outcomes. Moreover, It is crucial for addressing effectively bullying, as it is a problem student behaviour in Greek society as well.

In this context, the present research aims to explore teachers' views about family-school communication and collaboration regarding the extent to which they address effectively bullying. 150 primary education teachers from public schools in Rhodes participated in this research, which conducted in 2015. Results show that teachers endorse the importance of school-family collaboration for addressing bullying. In addition, they consider this collaboration important, as it has an important influence on children's attitudes to school, and their behaviour in school environment. Furthermore, they suggest that school-family collaboration may improve students' social skills, which can enhance their emotional development and reduce their social isolation from the peer group. Finally, they assert that school-family collaboration can empower children's relationship with their parents and teachers, and in the long term it can contribute in enhancing their school achievement.
\end{abstract}

Keywords: Bullying, school-family collaboration, communication, school climate.

\section{INTRODUCTION}

School bullying has increasingly become a topic of both public concern, research and conferences. It is a nationally reported epidemic which constitutes a prevalent social and educational concern. Moreover, school bullying is predictive of later delinquency. In this context, the current research aims to focus on studying and addressing bullying in Greek primary schools, which has become a major problem over the last decade. The main objective of this study is to examine communication and collaboration between school and family.

The present article initially attempts to conceptually clarify the core concepts of this study, communication and school bullying. Communication is not an one-way process. It is a multifaceted phenomenon. Human beings, as psychosomatic entities, achieve to exchange thoughts and feelings by using all senses and competencies (mental, emotional, social), internal motives and environmental stimuli. Communication involves encoding messages and it serves various goals in multiple levels of occupational, personal and social domains (Stamatis 2012). In this spirit, cooperation between educators and parents is an essential practice of school community. It involves

\footnotetext{
*Address correspondence to this author at the University of the Aegean, Dept. of Preschool Education and Educational Design, 1, Democratias ave., GR-851 32, Rhodes, Greece; Tel: 03022410 99149; E-mail: stamatis@rhodes.aegean.gr

"Co-author E-mail: enikolaou@aegean.gr
}

complex situations and is linked to rules, prerequisites, conditions and factors that determine its effectiveness.

\section{THEORETICAL FRAMEWORK}

The term school bullying, in Greek literature, is used interchangeably with school violence. Bullying is a type of aggressive behaviour that is characterized by explicit or implicit hostility, which is manifested in school environment. It involves direct or indirect antisocial behaviour, such as physical or verbal attack, spreading rumors, social stigmatization etc. These behaviours are repetitive, occur within school context and aim to hurt peers that are considered to be weaker. Bullying behaviours stigmatize students and inflict emotional or physical scars (Elinoff, Chafouleas, and Sassu 2004). Students exhibit aggressiveness, which involve dangerous and malicious behaviours that include intentional hurtfulness.

Theoretical models that attempt to explain aggressiveness are divided into two broad categories. The first category includes theoretical models maintaining that violent behaviour is genetically determined. The second category refers to theoretical models, which posit that violence is learned through interaction with the social environment (Chinas and Chrisafidis 2000). According to Espelage and Swearer (2003), school bullying is related to multiple factors, such as teachers' behaviour, peer group behaviour, family environment etc. It is also related to factors of 
the wider or proximal systems of social environment as well as to the individual traits of students. School bullying has multiple detrimental effects on students' physical and mental health as well as on mental, emotional and social development of both bullies and victims (Georgiadis, Vizakou, and Papastylianou 2009).

Large-scale studies have been conducted internationally for the prevention of school bullying and multiple prevention programs have been developed (Artinopoulou 2001). For example, Olweus (1994) has successfully implemented a prevention program in Norway, which focuses on creating a school environment that promotes warmth and provides students with positive stimuli. $\mathrm{He}$ also asserts that preventing bullying requires the joint efforts of both teachers and parents. One of the strategies in addressing bullying is to establish rules for prohibiting the manifestation of bullying behaviours and discouraging its tolerance. The program included several levels of intervention, such as the whole-school level, the classroom level, and the community level. The program consisted of instructional sessions, which involved classroom discussions, role-plays, reading books, and watching videos. School anti-bullying rules were also developed by both teachers and students. The intervention also included conflict resolution skills and anger management (Colvin et al. 1998).

Furthermore, Blair (2012) suggests that peer massage among young students is another strategy that could foster effectively addressing bullying. It has proven empirically to reduce violence and increase social inclusion, as it reduces stress and promotes bonding. It is based on the premise that pedagogical touch is essential to the psychosomatic development of children. Peer massage is done with clothes and only on head, shoulders, back, arms and hands and is always done by asking permission from students. It is facilitated and supervised by the teacher. Sociograms have shown that her method may contribute in learning students to respect gradually each other.

Undoubtedly, family and school play a fundamental role in upbringing and educating children and their collaboration is crucial to the socialization of children. The joint mission of school and family should be ensured by their constant and mutual support at the institutional and functional level (Dowling 2002).

Theoretical models that describe the relationship between school and family have been developed. Such models are the organizational, systemic, global, social, political as well as the theoretical model of Ryan \& Adams, etc. (Milonakou-Keke 2007; Georgiou 2011). According to Eipstein et al. (2008), family and school may collaborate by developing a mutual bi-directional communication which involves the following:

(1) Parenting, which refers to helping families establish home environments that support students,

(2) Communicating, which is related to designing and conducting effective forms of communication about school programs and children's progress,

(3) Volunteering, that is, recruiting and organizing parent support for school activities,

(4) Learning at home, (providing ideas to parents about how to help students with curriculumrelated activities,

(5) Decision making (parents' participation in decision making), and

(6) Collaborating with community.

Parent involvement is related to parents' participation in the educational process, aiming at contributing to their children's achievement. The most common reasons for parents' participation in educational process are the following:

(1) Surveillance and control of their children's behaviour,

(2) Assistance in homework, development of interests, and

(3) Collaboration with school for improving academic achievement, as it is reflected in students' test scores.

The frequency and quality of the relationship between school and family depends on parental factors (gender, socioeconomic level, etc.), children's individual traits (age, school achievement etc.), and school factors (teachers' attitudes, principal's attitude, curriculum etc.).

Literature suggests that there is a high correlation between school bullying and child-rearing practices. Many scientific approaches, such as social learning theory and systemic theory, attempt to explain family's influence on children's involvement in school bullying (Holt, Kantor, and Finkelhor 2009). Children's family 
experiences are associated with school bullying or victimization. Family factors associated with higher likelihood of engaging in bullying behaviour are authoritative parenting style, as well as harsh and punitive parents' attitude. Victims usually come from families with low level of negotiation, high levels of conflict and overprotective parents (Miller and Miller 2010).

Therefore, school bullying is a multifaceted phenomenon. Addressing bullying requires a multilevel and multi-component approach (Sheper and Nickerson 2010). Simultaneously, communication is a complex phenomenon of human behaviour. In addition, schoolfamily collaboration constitutes the most effective strategy for addressing bullying (Butler and Platt 2007).

Anti-bullying programs have been implemented and are currently implemented worldwide, in many countries. Furthermore, school bullying represents a significant problem worldwide. Specifically, Farrington and Ttofi (2009), conducted a meta-analysis of twenty nine (29) countries, including Greece. Their findings suggest that reducing school bullying is associated with interventions that include school-family communication as well as parents' and teachers' training in counteracting bullying behaviours. In this context, the European program " Partners in education-PIE" was devised to improve school -family relationships for addressing school bullying. The implementation of this program was successful in many countries, including Greece.

\section{METHOD}

The present study was based on the above theoretical framework and on the fact that school bullying is widespread. The objective of the current study was to explore communication between family and school in the context of school-family partnership with the aim of addressing school bullying. Specifically, this research study aims to explore the following:

(1) The frequency of bullying incidents in primary schools,

(2) The factors that contribute in the manifestation of school bullying and the extent to which the lack of cooperation between school and family is one of contributing factors,

(3) Under what circumstances the cooperation between school and family regarding school bullying is taking place,
(4) Teachers' views about parents' contribution in countering bullying, and

(5) Teachers' views about the most effective ways of counteracting bullying.

For the collection of data, a questionnaire was designed and distributed in a sample of teachers of primary education, in Rhodes, in October 2015. The sample of the current research was consisted of 150 teachers, 70 of them were men and 80 women who finally completed the provided questionnaire. The age range of the participants was among 25 and 55 year old.

The questionnaire was based on two main axes which were the foundation of the interpretation of research results. These axes were the importance of school-family collaboration in addressing bullying (theoretical approach, questions 1, 2, 3, 6, 7, 8) and the contribution of their communication in effectively addressing of bullying (experiential approach and good practices, questions $4,5,9,10,11,12$ ).

The present study was a descriptive study in the context of a survey. It was a short-scale structured research. The statistical package SPSS, 22.0 was used for the analysis of data.

\section{RESULTS AND DISCUSSION}

As the analysis of data revealed the majority of the teachers $(75 \%)$ who participated in this research stated that they often observe incidents of school bullying at school, although they rarely are informed of these incidents by students or their parents. The most bullying behaviours are perpetuated by boys $(89,8 \%)$. The results of these studies are consistent with previous research (Pepler and Craig 2000).

Furthermore, teachers believe that school bullying is reinforced by violent electronic games $(69,5 \%)$, the family environment $(53,1 \%)$, social norms $(50 \%)$ as well as lack of cooperation with parents $(45,3 \%)$. These findings support a growing body of literature asserting that school bullying is related to exposure to video game violence (Ferguson 2011). Moreover, these findings reflect that aggressive behaviour is the result of violent social models (Bandura 1973) and that the lack of collaboration between school and family is a crucial factor to the development of problem behaviours (Walsh 2004).

In addition, the teachers of this sample reported that seminars and workshops for raising awareness and 
addressing bullying in the context of formal educational policy, are rarely organized $(25,8 \%)$ or never $(60,2 \%)$. Nevertheless, the majority supports that their school units implement programs for counteracting bullying. These programs include communication, school-family collaboration and have positive effects in dealing with school bullying. These percentages are consistent with relevant literature suggesting that the effectiveness of programs aiming at reducing bullying behaviours is related to parents' involvement in these programs for developing strategies to counter bullying. Parents' involvement as a component of formal school policy, is crucial to addressing this phenomenon.

The importance of school-family collaboration is evident in teachers' answers to the question "How often do you communicate with parents about their children' s behaviour?". The $64 \%$ of teachers stated that they communicate with parents once a month about their children's behaviours manifested at school. These findings are in contrast with previous research (Johnson 2008; Georgiou 2008) which supports that there is limited communication between parents and teachers on a regular basis for dealing with school bullying.

Moreover, the majority of teachers (79,7\%) argue that collaboration and communication between school and family is fundamental to counteracting bullying, as they assert that it is linked to children's positive attitudes toward school $(96,1 \%)$, to the improvement of their behaviour $(88,3 \%)$ and to the gradual reduction of bullying incidents (83,6\%). These results are consistent with the international and Greek literature supporting that school-family collaboration is a major contributing factor to children's positive attitudes toward school, to the improvement of their achievement and to the reduction of aggressiveness, which is the foundation of school bullying (Butler and Platt 2007; Artinopoulou 2001).

The above research findings are in conjunction with the relevant literature asserting that teachers can aid in countering students' bullying behaviours through pedagogical activities (Stevens, Bourdeaudhuij, and Van Oost 2000).

In addition, literature suggests that the most successful school-based interventions for preventing school bullying use a whole-school approach that address bullying as a systemic problem. Social and emotional learning programs are an important component of whole-school approach, which is directed at different levels of school organization (Vreeman and
Carroll 2007). The effectiveness of social and emotional learning interventions is linked to parents' involvement (Hoagwood et al., 2007). These programs often include a parent component that strengthen parents' and children's emotional skills. Family involvement can enhance positive outcomes in children's social and academic development. For example, the Incredible Years series program includes a training program for parents (Webster-Stratton and Reid 2004). Parenting programs can reduce externalizing behaviours and provide parents with strategies for supporting their children's social and emotional development, as they have a positive effect on social competence. Further, parent training could enhance relationships and communication between parents and children and develop parents' ability to use alternative methods for disciplining their children. Parents learn to interact with their children affectionately, respect their feelings and demonstrate empathy. Simultaneously, positive parents-child interactions are strengthened, as they are trained in relation-building communication skills that improve communication patterns among families. Therefore, parents' participation in addressing school bullying is crucial (Butler and Platt 2008).

Finally, the most effective attempts to counter school bullying are those that approach school bullying by involving all members of school community.

\section{CONCLUSIONS}

According to the above mentioned results and furthermore the discussion and interpretation of them the core conclusions of this research could be summarized as following:

(1) The teachers of the sample frequently observe incidents of school bullying at their school. Students or parents rarely report these incidents.

(2) Most teachers support that bullying behaviours are related to the exposure to electronic games' violence, to the social norms that the family environment adopts, and the lack of collaboration between educators and parents.

(3) School units are implementing anti-bullying programs. These programs include communication and cooperation between schoolfamily and are effective in countering bullying. Though, the above mentioned programs are rarely organized by schools and not systematically. 
(4) Most teachers stated that they communicate once a week with parents for discussing their children's behaviour and they argue that this is not enough for effectively addressing bullying.

(5) Most teachers argue that school-family collaboration and communication regarding bullying behaviours is very important, as it is associated with students' positive attitudes toward school, with the improvement of their behaviour and the gradual reduction of bullying instances.

(6) Most teachers support that cooperation with school counsellor or social services is the most effective way of dealing with bullying, as well as the support, discussion and giving advice to the children actively involved in bullying instances either as bullies or as victims.

The general conclusion drawn from the aforementioned results, is that the participants of this research, which are teachers of primary education and work at public schools in Rhodes city, argue that school-family collaboration is fundamental to effectively addressing the widespread phenomenon of school bullying, which is detrimental to students' development. Moreover, they argue that lack of communication between school and family is significantly contributing to school bullying, a multidimensional phenomenon, which is a prevalent concern for our school community.

\section{SUGGESTIONS}

School bullying involves anti-social and antidemocratic behaviours that need immediate effective interventions. Based on the aforementioned research data, the following suggestions are made:

(1) It is crucial that teachers encourage communication with parents on a regular basis for bullying issues so that they prevent bullying,

(2) Students and teachers should establish zero tolerance rules for school bullying,

(3) School units could develop didactic and educational strategies for counteracting bullying. These strategies include conflict resolution and anger management programs,

(4) It is essential that didactic activities related to school bullying are implemented within classroom with the aim of developing gradually the value of cooperation and team spirit. Such didactic activities could be in the context of cooperative learning, literature-based lessons, role-playing, watching videos, whole-class discussions for bullying issues etc.,

(5) Seminars for raising teachers', parents' and students' awareness for school bullying are also essential,

(6) It is important that teachers actively listen to students that discuss bullying instances and encourage them to provide detailed reports related to this bullying instances,

(7) Training teachers in communication skills is also vital for being able to manage a variety of behaviours including crisis intervention skills.

Undoubtedly, all the above suggestions could contribute in developing effective communication and school-family collaboration in the context of effectively addressing bullying. As in many other beings, violence constitutes a common human feature which may be hidden or apparent in the daily behaviour of everybody. If it is so, then bullying seems to be the reflection and extension of violent behaviour from adults to children and youth. Also, it seems to be a reflection of the social relationships to school communities which are trending to become copies of the bad face of society. Collaboration among educators and parents or school and family members who are eager in working together could addressing bullying in a positive way.

\section{LIMITATIONS AND STRENGTHS}

Like many other studies this one was not without limitations as well. Most of limitations were related to the small sample size which was originated by the same educational area. Furthermore, the questionnaire for data collection was consisted of only twelve questions. All of them were focused on the main purpose of the study. As the bullying phenomenon is not very well investigated in Greek schools, the present study sheds light on several aspects of bullying and moreover illuminates the potentialities for collaboration between educators and parents against the violence of childhood.

\section{REFERENCES}

Artinopoulou, Baso. 2001. Violence in School. Researches and Politics in Europe. Athens: Metaixmio.

Babalis, Thomas. 2005. Child Socialization in the Classroom. The role of Teacher. Athens: Atrapos. 
Bandura, Alfred. 1973. Aggression: A social learning analysis. USA: Prentice Hall.

Blair, Thea. 2012. From Bullying to Belonging: How Peer Massage Relieves Social Stress. Retrieved by http://www. waldorftoday.com/2012/10/from-bullying-to-belonging-howpeer-massage-relieves-social-stress/ on 20-01-2015.

Butler, John L. VI and Rhi Anna Lynn Platt. 2007. "Bullying: A Family and School System Treatment Model." The American Journal of Family Therapy 36(1):18-29. http://dx.doi.org/10.1080/01926180601057663

Chinas, Panagiotis and Kostas Chrysafides. 2000. Aggressivity in the School. Proposals for Prevention and Confrontation. Retrieved by http://www.pi-schools.gr/download/lessons/ social/entypa/epithet1.pdf on 14-05-2015.

Colvin, Geoff, Tary Tobin, Kelli Beard, Shanna Hagan and Jeffrey Sprague. 1998. "The School Bully: Assessing the Problem, Developing Interventions, and Future Research Directions." Journal of Behavioral Education 8(3):293-319. http://dx.doi.org/10.1023/A:1022819213727

Dowling, Grahame. 2002. Creating Corporate Reputations: Identity, Image, and Performance. Oxford University Press.

Ellinoff, Mahri J., Sandra M. Chafouleas and Kari A. Sassu. 2004. "Bullying: Considerations for Defining and Intervening in School Setting." Psychology in the Schools 41(8):887-897. http://dx.doi.org/10.1002/pits.20045

Epstein, Joyce L., Mavis Sanders, Steven Sheldon, Beth S. Simon, Karen Clark C. Salinas, Natalie R. Janson, Frances L. Van Voorhis, Cecelia S. Martin, Brenda G. Thomas, Marsha D. Greenfield, Darcy J. Hutchins and Kenyatta J. Williams. 2008. School, Family, and Community Partnerships. Your Handbook for Action. Thousand Oaks, CA: Corwin Press.

Espelage, Dorothy L. and \& Susan M. Swearer. 2003. "Research on School Bullying and Victimization: What Have we Learned and Where do we Go From Here?" School Psychology Review 32(3):365-383.

Farrington, David P. and Maria M. Ttofi. 2009. School-Based Programs to Reduce Bullying and Victimization. USA: Campbell Systematic Reviews.

Ferguson, Harry. 2011. Child Protection Practice. GB: Palgrave Macmillan.

Georgiades, Stelios, Semeli Vizakou and Dona Papastilianou. 2009. The Correlation Between Violence Against Children Within the Family and Juvenile Delinquency. Retrieved by http://www.familyviolence.gov.cy/upload/research/erevna_20 09june_executive_summary_en.pdf on 12-03-2015.

Georgiou, Stelios (2008). "Bullying and Victimization at School: The Role of Mothers." British Journal of Educational Psychology 78:109-125. http://dx.doi.org/10.1348/000709907X204363

Georgiou, Stelios. 2011. The Relation Between School and Family and Child Development. Athens: Diadrassi.

Hoagwood, Kimberly E, Olin Serene S., Kerker, Bonnie D., Kratochwill, Thomas R., Crowe Maura and Noa Saka (2007). "Empirically based school interventions targeted at academic and mental health functioning." Journal of Emotional and Behavioural Disorders, 15(2):66-92.

http://dx.doi.org/10.1177/10634266070150020301

Holt, Melissa K., Glenda Kaufman Kantor and David Finkelhor. 2009. "Parent/Child Concordance About Bullying Involvement and Family Characteristics Related to Bullying and Peer Victimization." Journal of School Violence 8(1):42-63. http://dx.doi.org/10.1080/15388220802067813

Hudson, Patricia E., R. Craig Windham and Lisa M. Cooper. 2005 "Characteristics of School Violence and the Value of FamilySchool Therapeutic Alliance." Journal of School Violence 4(2):133-146. http://dx.doi.org/10.1300/J202v04n02 08

Johnson, Tracy A. 2008. "The Impact of Parent Involvement in Bullying at the Middle School Level". PhD dissertation, Bowie State University.

Miller, Holly Ventura and J. Mitchell Miller. 2010. "School-Based Bullying Prevention." P.p. 817-819 in Encyclopedia of Victimology and Crime Prevention. Vol. 2, edited by B. S. Fisher, and St. P. Lab. Los Angeles: SAGE. http://dx.doi.org/10.4135/9781412979993.n274

Mylonakou-Keke, Iro. 2007. Modern Theoretical Issues on Communication Between School, Family and Community. Athens: Atrapos.

Olweus, Dan. 1994. "Annotation: Bullying at School. Basic Facts and Effects of a School Based Intervention Program." The Journal of Child Psychology and Psychiatry, 35(7):11711190.

http://dx.doi.org/10.1111/j.1469-7610.1994.tb01229.x

Pepler, Debra J. and Wendy Craig. 2000. Making a Difference in Bullying. Retrieved by http://www. peacefulschoolsinternational.org/wp-content/uploads/making_a_difference_ in_bullying.pdf on 25-07-2015.

Sheper, Yiping C. and Amanda B. Nickerson. 2010. "Anti-Bullying Practices in American Schools: Perspectives of School Psychologists." Psychology in the Schools 47(3):217-229.

Stamatis, Panagiotis J. 2013. Communication in Education. Athens: Diadrassi.

Stevens, Veerle, Ilse De Bourdeaudhuij and Paulette Van Oost. 2010. "Bullying in Flemish Schools: An Evaluation of Antibullying Intervention in Primary and Secondary Schools." British Journal of Educational Psychology, 70(2):195-210. http://dx.doi.org/10.1348/000709900158056

Vreeman, Ratchel C. and Aaron E. Carroll (2007). "A systematic review of school-based interventions to prevent bullying." Archive of Pediatrics and Adolescent Medicine, 161(1):78-88. http://dx.doi.org/10.1001/archpedi.161.1.78

Walsh, Froma. 2004. "The Concept of Family Resilience: Crisis and Challenge." Family Process 35(3):261-281. http://dx.doi.org/10.1111/j.1545-5300.1996.00261.x

Webster-Stratton, Carolyn and Jamila Reid (2004). "Strengthening social and emotional competence in young children-The foundation for early school readiness and success." Infants and Young Children, 17(2):96-113.

http://dx.doi.org/10.1097/00001163-200404000-00002

\section{DOI: http://dx.doi.org/10.6000/1929-4409.2016.05.09}

(C) 2016 Stamatis and Nikolaou; Licensee Lifescience Global.

This is an open access article licensed under the terms of the Creative Commons Attribution Non-Commercial License (http://creativecommons.org/licenses/by-nc/3.0/) which permits unrestricted, non-commercial use, distribution and reproduction in any medium, provided the work is properly cited. 